eastern North Atlantic, an area where historical data have been scarce. In the basement of Charlottenlund Castle (the former ICES headquarters), Dr. Dooley discovered an additional 20,000 cards of geographically sorted Danish data, also not in the computer database. Some of these cards contained data from the 1896 Ingulf Expedition in the Norwegian Sea.

The workshop participants agreed that initially the archaeology effort should concentrate on hydrographic profile data, including nutrient data. It was felt that the data-archaeology approach developed with these initial data types would be applicable to other data types. It was also agreed that certain highpriority activities should begin as soon as possible.

For example, the NODC and WDCA agreed to begin producing data distribution maps of their hydrographic data holdings on a country-by-country basis for decadal, pentadal, or interannual time periods (to assure that individual cruise tracklines will be visible). Appropriate maps will be sent to data centers and data-gathering institutions in every country. From these maps, institutions will be able to tell whether all their data are in the archive, and the total extent of archived data. The World Data Center A will also help other countries produce data-distribution maps of their holdings if such help is required.

An inventory will be compiled of manuscript and analog data sets of which the workshop participants are now aware. With this information, priorities for expending resources to digitize data can be decided upon. By distributing this list to various data centers, it also can be determined whether any of these data already have been digitized. This inventory will be continually updated as new historical data sets are discovered.

The participants thought that data archaeology was an activity that would benefit from a newsletter. A frequently published Ocean Data Archaeology Newsletter would help make the scientific and data-management communities aware of data-archaeology efforts and would provide the kinds of information that would stimulate the discovery of unarchived historical data sets, such as data distribution maps, lists of known manuscript and analog data, updates on newly discovered data, rumors and leads that need substantiation, articles about research and archaeology projects at various institutions, and even interesting historical articles dealing with cruises and data. In addition, a telemail bulletin board (or mailbox) would allow for rapid communication about archaeology issues and potential data sets.

These techniques will play an important role in discovering and acquiring historical data sets. Many other techniques were proposed and discussed, including visiting scientist programs and joint research projects using historical data; monetary support of "regional archaeology centers" and institutions with historical data in need of digitization and quality control; use of an automated ROSCOP/cruise report system to point to data collected but never archived; bibliographic searches of published and gray literature to discover additional historical data sets; use of the WDC-A Catalogue of Data and Catalogue of Accessioned Publications; compilation of an inventory of researchers and data managers working with particular data types; the development of a personal-computer program for quality-controlled data entry and format conversion to aid manual digitization efforts at some institutions; and the compilation of instrumentation and quality control methods used over the years for particular data types.

Workshop participants included Harry Dooley, ICES, Copenhagen, Denmark; Nikolai Mikhailov, World Data Center B, Obninsk, USSR: Arkady Alekseev, Pacific Oceanological Institute, USSR Academy of Science, Vladivostok, USSR; Shin Tani, Japanese Oceanographic Data Center, Tokyo, Japan; Ben Searle and Gary Hopwood, Australian Oceanographic Data Center, North Sydney, Australia; Kee-Soo Nam, Korean Ocean Research and Development Institute, Seoul, Korea; Ricardo Rojas, Instituto Hidrografico de la Armada, Valparaiso, Chile; Joe Reid and Warren White, Scripps Institution of Oceanography, LaJolla. CA, USA; Ronald Moffat, WDC-A/US NODC; Sydney Levitus, US NODC: Pembroke Hart. WDC-A Coordination Office, US National Academy of Sciences; and Bruce Parker (chairman), WDC-A/US NODC.

For a copy of the Report of the Oceanographic Data Archaeology Workshop or to be added to the mailing list for the newsletter, telephone Robert Gelfeld at (202) 606-4571.

\title{
Let Roger ReVelle Speak fOR Himself
}

\section{By Walter H. Munk and Edward A. Frieman*}

$I_{n}$ IN THE April 1991 issue of the Cosmos Club Journal, Singer, Revelle and Starr published a paper, "What To Do About Greenhouse Warming: Look Before You Leap." Roger died in July 1991. One year later, in a discussion of Senator Gore's book Earth In Balance, Gregg Easterbrook notes that Senator Gore failed to mention that "before his death last year, Revelle published a paper that concludes, 'The scientific basis for greenhouse warming is too uncertain to justify drastic action at this time." "Italics ours; see Green

* W.H. Munk, E.A. Frieman, Scripps Institution of Oceanography. University of California at San Diego. La Jolla, CA 92093, USA.
Cassandras, The New Republic, 6 July 1992.) Easterbrook goes on to say. "A lifetime of study persuaded Revelle that carbon emissions should be restricted, but are far less hazardous than initially feared."

S. Fred Singer wrote the paper and, as a courtesy, added Roger as a co-author based upon his willingness to review the manuscript and advise on aspects relating to sea-level rise. The whole, it seems to us, is rather less than the sum of its parts, relative to Roger's stance on these issues.

The key is the use of the word drastic. Roger's last written statement on the subject was "What Can We Do About Climate." presented at the AAAS (American Association for the Advancement of Science) session, Climate Change: Scientific Uncertainties and Policy Responses in New Orleans on 16 Feb- ruary 1990 . It outlines a possible set of actions designed to mitigate or delay climatic warming. It includes attempts to modify society's use and mix of fuels. While these may not be viewed as drastic, there is also no evidence that he believed that "emissions . . . are far less hazardous than initially feared."

Roger attended a joint meeting of the American Philosophical Society and the Royal Society in London in May 1991, just a few months before he died. One of us was present and noted that in a public discussion of foreign climate research, he criticized the lack of certain types of measurements, which he believed necessary to understand the phenomena. Roger's strongly held personal conviction called for informed activism, a combination of research and public policy action. a view he held at the time of his death. 